\title{
Prediction of interaction between a side overflow and bed-load transport in a channel with semi- empirical approaches
}

\author{
Burkhard Rosier, Jean-Louis Boillat, and Anton J. Schleiss
}

\begin{abstract}
Side weirs are free overflow regulation and diversion structures commonly encountered in flood protection engineering. The lateral loss of water reduces the bed-load transport capacity in the main channel, leading to local sediment deposition near the side overflow. As a consequence, the design overflow is increased in an uncontrolled way. Since this flow-sediment interaction in such a channel has not been studied so far, systematic flume experiments have been performed. Based on these experiments, a two-dimensional empirical model to describe the longitudinal evolution of the aggraded channel reach near the weir has been developed. In addition, a simple and straightforward approach for direct estimation of the side overflow in presence of bed-load transport has been established. To be generally applicable in engineering practice, all input variables are expressed in terms of dimensionless parameters. Finally, the application of the models is demonstrated in a case study on the Rhone River in Switzerland.
\end{abstract}

Key words: side overflow, sediment transport, bed morphology, deposition, semi-empirical model, laboratory tests.

Résumé : Les seuils à déversoir latéral sont des structures de contrôle et de détournement à écoulement libre régulièrement utilisées en ingénierie de lutte contre les inondations. La perte latérale d'eau permet de réduire la capacité de transport de la charge de fond dans le chenal principal, engendrant ainsi une déposition locale des sédiments près du déversoir latéral. Le débordement servant aux calculs est donc augmenté de manière non contrôlée. Des expériences systématiques de canal sur appuis ont été réalisées puisque cette interaction écoulement-sédiments dans un tel canal n'avait jamais été étudiée. Basé sur ces expériences, un modèle empirique bidimensionnel a été développé afin de décrire l'évolution longitudinale de la portion du canal alluvial à proximité du déversoir. De plus, une approche simple et explicite d'estimation directe de l'écoulement latéral avec transport de la charge de fond a été déterminée. Pour être applicables à l'ingénierie, les variables d'entrée sont exprimées en termes de paramètres sans dimensions. Finalement, l'utilisation des modèles est démontrée sur une étude de cas du Rhône en Suisse.

Mots-clés : seuil à déversoir latéral, transport de sédiments, morphologie du lit, déposition, modèle semi-empirique, essais en laboratoire.

[Traduit par la Rédaction]

\section{Introduction}

Side weirs, also known as lateral weirs, and overflow dams are free overflow regulation and diversion devices commonly encountered in river engineering. They are set into the bank of a river levee, allowing to spill a part of the discharge over their crest when the surface of the flow in the main channel exceeds a certain level. The flow over a side weir is a typical case of spatially varied flow with decreas-

Received 13 October 2008. Revision accepted 25 June 2009.

Published on the NRC Research Press Web site at cjce.nrc.ca on 13 November 2009.

B. Rosier, ${ }^{1,2}$ J. Boillat, and A.J. Schleiss. Laboratory of Hydraulic Constructions (LCH), Ecole Polytechnique Fédérale de Lausanne (EPFL), Station 18, 1015 Lausanne, Switzerland.

Written discussion of this article is welcomed and will be received by the Editor until 31 March 2010.

${ }^{1}$ Corresponding author (e-mail: burkhard.rosier@fichtner.de).

${ }^{2}$ Present address: Fichtner GmbH \& Co. KG, Engineering and Consulting - Worldwide, Sarweystraße 3, 70191 Stuttgart, Germany. ing discharge. Until now, research has focused on the determination of an appropriate discharge coefficient to estimate the total overflow discharge. Sharp-crested side weirs in rectangular channels have been studied extensively by Subramanya and Awasthy (1972), Ranga Raju et al. (1979), Hager (1987), Singh and Satyanarayana (1994), Ghodsian (2003), and Khorchani and Blanpain (2005). Since most studies refer to irrigation or drainage engineering (Hager 1986; Borghei et al. 1999; and Crobeddu and Bennis 2006), usually a fixed channel bottom is assumed. Natural rivers have a mobile bed, and in flood protection projects, flowsediment interaction induced morphological processes have to be taken into account.

The lateral loss of water decreases the sediment transport capacity in the main channel, yielding to sediment aggradation and the formation of a local sediment deposit near the weir. The reduced cross section generates backwater effects through contraction and expansion losses. As a consequence, the head over the side weir rises and the side overflow intensity rises as well. Since the extent of the sediment deposition phenomena is not known a priori, the design discharge is increased in an unforeseen way.

The interaction of a side overflow with bed-load transport 
and bed morphology has not been studied so far. Therefore, systematic flume experiments have been performed (Rosier 2007b). Based on these experiments, a semiempirical approach for the prediction of the longitudinal bed evolution near the overflow is developed. The aggraded channel reach is mainly characterized by the location and height of the maximum bed elevation and a shape factor. The input parameters for the parametrical description of the bed evolution with a Maxwell distribution function are expressed in terms of dimensionless geometric channel and side weir variables as well as hydraulic parameters and bed-load transport relations. For the implementation of the aggradation model into a flow calculation program, a reference point is established.

In addition to the bed elevation model, a method for direct estimation of the side overflow in presence of a mobile channel bottom is developed using the Manning equation and the general equation of weirs. The models allow a simple and straightforward estimation of the interaction of a side overflow with morphological bed changes in engineering practice. This is illustrated in a case study on the Rhone River in Switzerland.

\section{Flume experiments}

The experiments have been conducted in a rectangular prismatic glass-sided flume being $40.00 \mathrm{~m}$ long, $2.00 \mathrm{~m}$ wide, and $1.20 \mathrm{~m}$ deep. The initial bottom slope of the mobile bed has been achieved by adjusting the sediment layer. The flume was subdivided longitudinally into two separate channels. The first channel, $20.00 \mathrm{~m}$ long and $1.50 \mathrm{~m}$ wide, represents the actual testing facility with the mobile bed. The second one, $0.47 \mathrm{~m}$ wide, constitutes a lateral channel for the evacuation of the diverted discharge (Figs. 1 and 2).

The initial bottom slope $\left(S_{0}\right)$ varied between $0.1 \%$ and $0.4 \%$. All experiments have been performed under steady flow conditions. The upstream discharge $\left(Q_{1}\right)$ comprised a range of $0.098-0.222 \mathrm{~m}^{3} / \mathrm{s}$ and was kept constant throughout each experiment. The initial crest height of the side weir $\left(w_{\mathrm{D}}\right)$ was fixed to $0.10 \mathrm{~m}$, and the weir crest length $\left(L_{\mathrm{D}}\right)$ varied in the range of $3.00 \mathrm{~m}$ (test series B), $6.00 \mathrm{~m}$ (test series $\mathrm{C})$, and $2 \times 2.50 \mathrm{~m}(=5.00 \mathrm{~m})$ (test series D). As a reference case, an experiment without a side weir was performed (test series A). The characteristics of all test series are given in Table 1.

The side weir was located on the right channel bank $5.00 \mathrm{~m}$ or 40 flow depths from the main-channel inlet (test series B). For test series C and D, the position of the side overflow was $3.50 \mathrm{~m}$ or 32 flow depths and 26 flow depths, respectively, downstream from the main-channel inlet. The weir crest was horizontal and rectangular with a crest width of $0.025 \mathrm{~m}$.

The bed material used in all tests consists of sand having a median diameter of $d_{50}=0.72 \mathrm{~mm}$, a geometric sorting coefficient of $\sigma_{\mathrm{g}}=2.95$, a density of $\rho_{\mathrm{s}}=2650 \mathrm{~kg} / \mathrm{m}^{3}$, and a bulk density of $\rho_{\mathrm{s}}=1447 \mathrm{~kg} / \mathrm{m}^{3}$ for a porosity of $p=$ $45.4 \%$. The properties of the bed material are typical for the Rhone River in Switzerland.

For each experiment, the water depth was recorded continuously with a frequency of $1 \mathrm{~Hz}$ in the centre line of the main-channel by the use of 15 ultrasonic gauges (Fig. 2).
Fig. 1. Laboratory setup with main-channel, mobile bed, side weir, and evacuation channel.

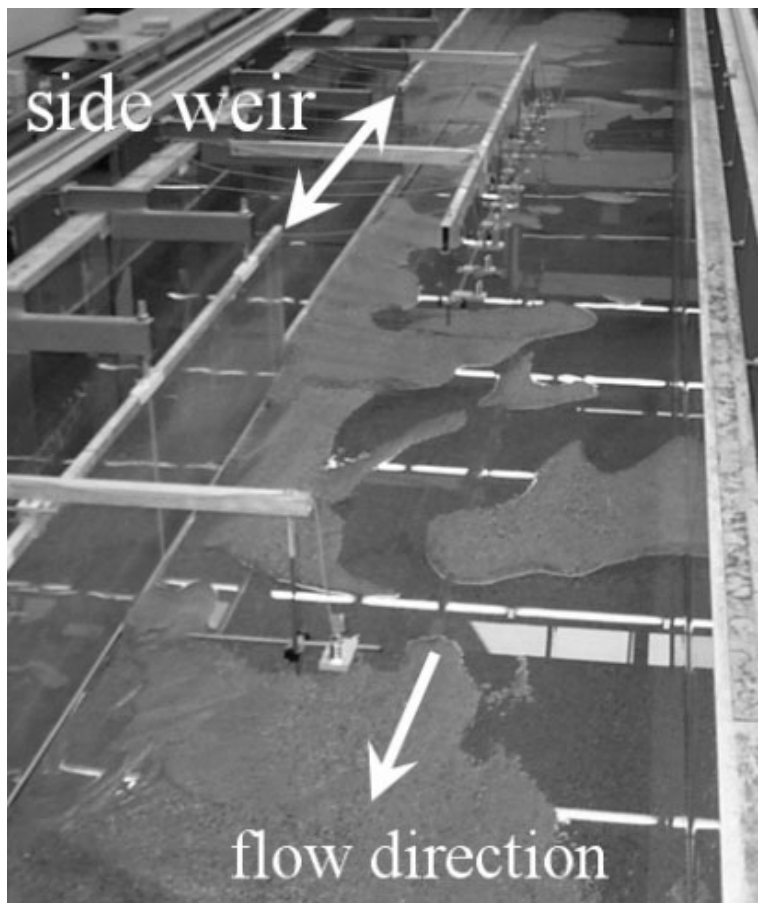

Fig. 2. Definition sketch (plan view) of the experimental setup (test series $\mathrm{B}$, number of side weirs $n_{\mathrm{D}}=1$, side weir crest length $L_{\mathrm{D}}=$ $3 \mathrm{~m}$ ) and arrangement of water level (US) and velocity (UVP) recordings.

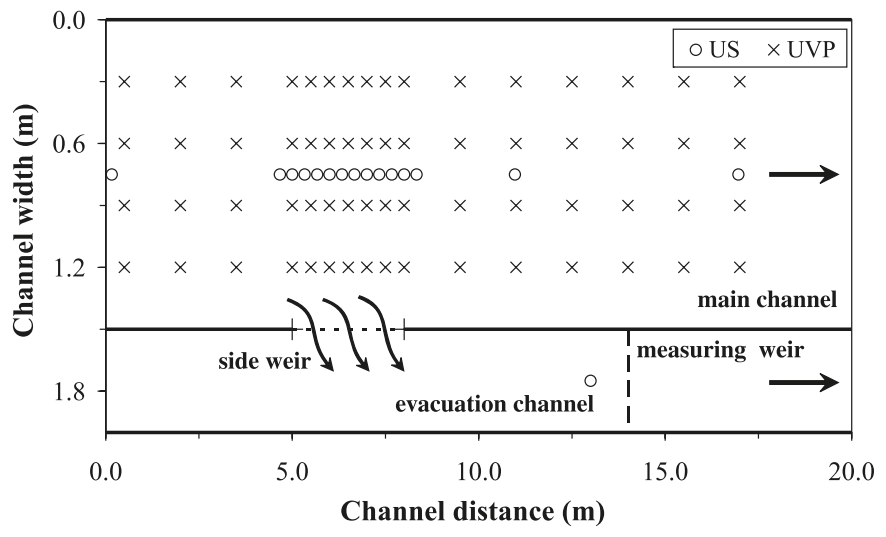

The accuracy of the water level measurement is $\pm 0.5 \mathrm{~mm}$. The 2D velocity field was measured with an ultrasonic Doppler velocity profiler (UVP), allowing to obtain instantaneously a 1D velocity profile over the entire flow depth (Metflow 2000). The probes had an emitting frequency of $2 \mathrm{MHz}$. Velocity profiles were recorded every $30 \mathrm{~min}$ for 16 cross sections (Fig. 2).

The final bed topography was recorded using digital photogrammetry (Rosier et al. 2004). A grid resolution of the digital elevation model $(\mathrm{DEM})$ of $2.5 \mathrm{~cm} \times 2.5 \mathrm{~cm}$ was chosen. The vertical precision of the DEM is $\pm 2.5 \mathrm{~mm}$, which corresponds to about $3.5 d_{50}$. A detailed description of the experimental setup, the measurement procedure, and the data analysis is given in Rosier (2007b). 
Table 1. Overview of the test series and parameters studied. The slope $\left(S_{0}\right)$ corresponds to the initial bottom slope. The Froude number $\left(F r_{1}\right)$ and the side overflow discharge $\left(Q_{\mathrm{D}}\right)$ refer to the final experimental conditions. The value for $Q_{\mathrm{D}}$ has not been imposed.

\begin{tabular}{|c|c|c|c|c|c|c|c|c|}
\hline $\begin{array}{l}\text { No. of } \\
\text { run }\end{array}$ & $\begin{array}{l}\text { No. of weirs, } \\
n_{\mathrm{D}}(-)\end{array}$ & $\begin{array}{l}\text { Length of } \\
\text { weir crest, } \\
L_{\mathrm{D}}(\mathrm{m})\end{array}$ & $\begin{array}{l}\text { Bed slope, } \\
S_{0}(\%)\end{array}$ & $\begin{array}{l}\text { Upstream } \\
\text { Froude num- } \\
\text { ber, } F r_{1}(-)\end{array}$ & $\begin{array}{l}\text { Upstream } \\
\text { discharge, } Q_{1} \\
\left(\mathrm{~m}^{3} / \mathrm{s}\right)\end{array}$ & $\begin{array}{l}\text { Side } \\
\text { overflow, } \\
Q_{\text {D }}\left(\mathrm{m}^{3} / \mathrm{s}\right)\end{array}$ & $\begin{array}{l}\text { Sediment } \\
\text { supply, } Q_{\text {sb }} \\
(\mathrm{kg} / \mathrm{min})\end{array}$ & $\begin{array}{l}\text { Test duration, } \\
t \text { (min) }\end{array}$ \\
\hline A01 & - & - & 0.2 & 0.560 & 0.153 & - & 15.25 & 120 \\
\hline B02 & 1 & 3.00 & 0.2 & 0.763 & 0.181 & 0.052 & 17.73 & 183 \\
\hline B03 & 1 & 3.00 & 0.4 & 0.672 & 0.177 & 0.041 & 9.10 & 117 \\
\hline B04 & 1 & 3.00 & 0.1 & 0.753 & 0.098 & 0.004 & 9.67 & 245 \\
\hline B06 & 1 & 3.00 & 0.3 & 0.625 & 0.148 & 0.044 & 17.67 & 138 \\
\hline $\mathrm{C} 01$ & 1 & 6.00 & 0.2 & 1.072 & 0.160 & 0.030 & 9.56 & 125 \\
\hline $\mathrm{C} 02$ & 1 & 6.00 & 0.2 & 1.012 & 0.197 & 0.032 & 42.69 & 120 \\
\hline $\mathrm{C} 03$ & 1 & 6.00 & 0.2 & 1.916 & 0.221 & 0.071 & 51.76 & 120 \\
\hline $\mathrm{C} 04$ & 1 & 6.00 & 0.2 & 0.943 & 0.179 & 0.028 & 39.82 & 120 \\
\hline $\mathrm{C} 05$ & 1 & 6.00 & 0.2 & 0.978 & 0.181 & 0.038 & 39.82 & 120 \\
\hline D05 & 2 & 2.50 & 0.2 & 0.825 & 0.150 & 0.009 & 19.91 & 120 \\
\hline
\end{tabular}

Fig. 3. Three-dimensional view of the final bed morphology for experiment C01. The dotted line indicates the location of the side weir. Note: For better visibility of the deposit, the left and right channel bank are inverted.

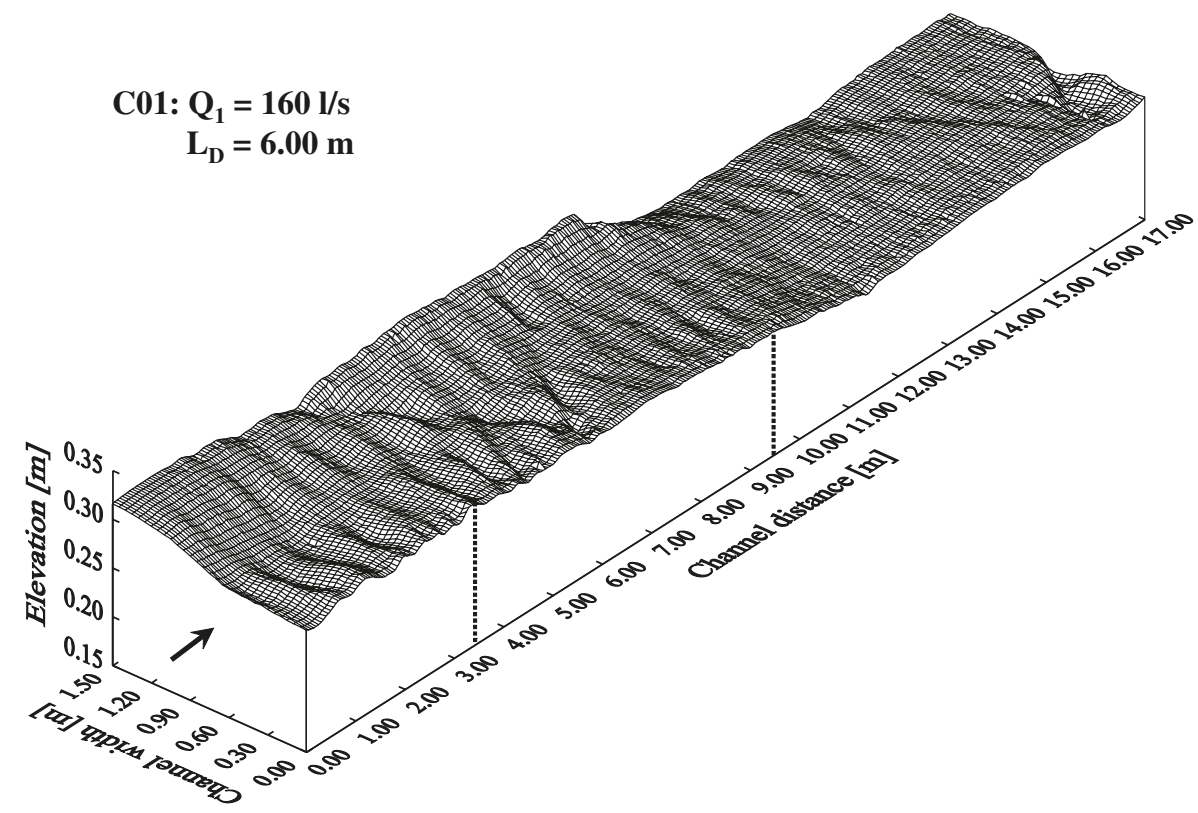

\section{Formation of a local sediment deposit near the side weir}

Aggradation (and erosion) is caused by the disturbance of the equilibrium between the sediment transport capacity of the main-channel and the sediment supply. Since no sediments have been transported over the weir, the sediments fed at the channel entrance have to be transported by a reduced flow downstream of the side overflow. To compensate for the reduced transport capacity and to reestablish equilibrium transport conditions, the channel slope increases by deposition of sediments in the weir reach and downstream of the weir (Fig. 3). The relative average increase is expressed by the ratio of the final bottom slope to the initial one $\left(S_{0, \text { fin }} / S_{0, \text { ini }}\right)$. For test series $\mathrm{B}$, the ratio is 2.16 (range 0.94/3.40); for test series C, it is 2.03 (range 0.99/2.83); and for series D, a value of 1.31 (range $0.87 / 2.00$ ) pertained. The initial slopes are presented in Table 1.

In Fig. 4, final bed surface profiles for each test series are presented. Although occasionally erosion or deposition is present in the channel reach upstream of the weir, almost equilibrium sediment transport conditions can be observed. Immediately upstream of the weir, the flow is attracted by the weir, and slight erosion due to accelerated flow conditions occurs. As soon as the weir is reached, the main-channel discharge and hence the sediment transport capacity is reduced 
Fig. 4. Final longitudinal bed surface elevation profiles for test series B, C, and D (moving average). The initial slope for test series B corresponds to the average slope of the six experiments. The bold dashed vertical lines indicate the location of the side weir (crest height at $z=0.35 \mathrm{~m}$ ).
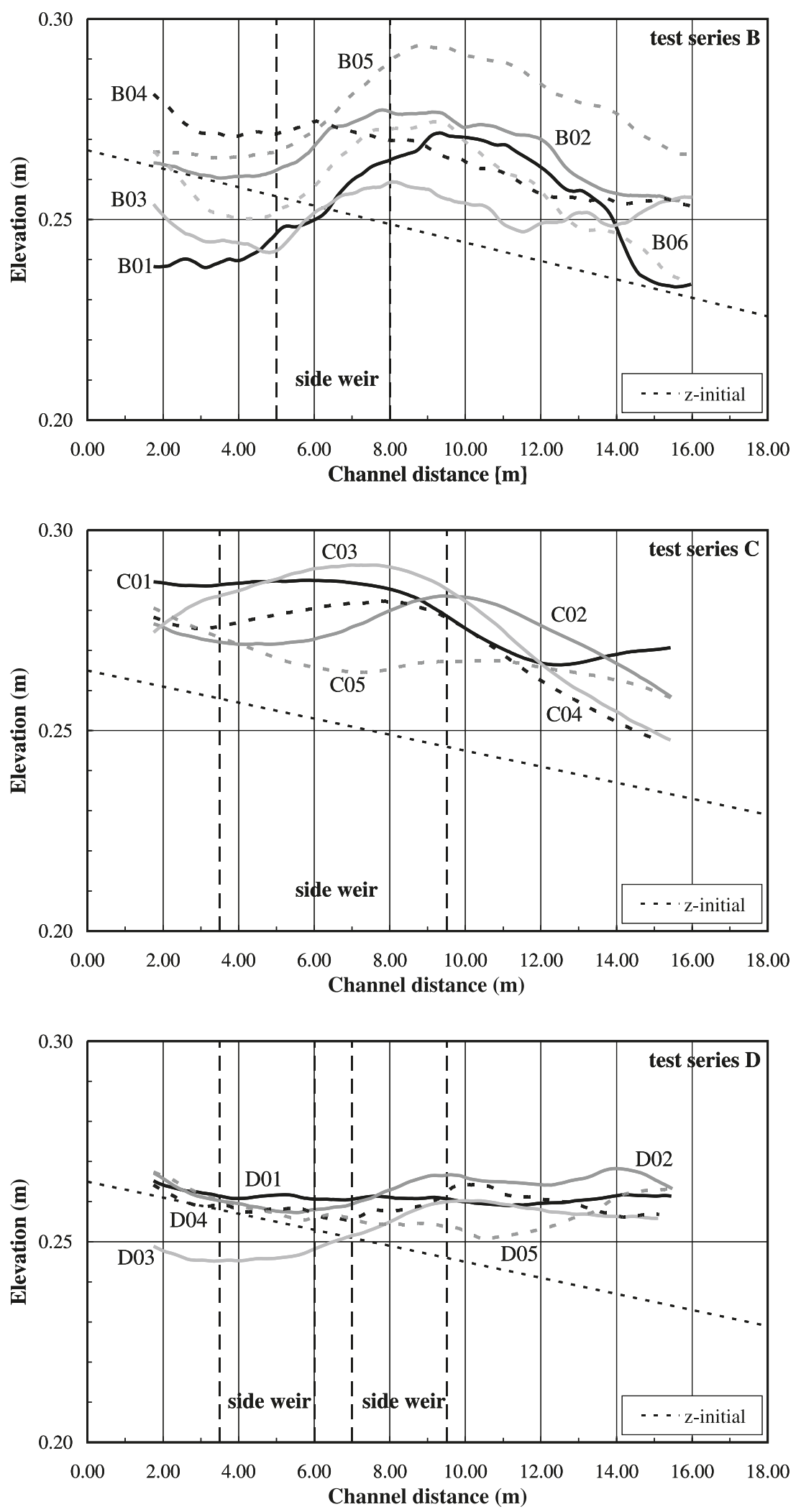
and aggradation occurs. Maximum deposition is observed at the downstream weir corner. For experiments D01 and D04, a rather small deposit at the first weir can be observed. However, this deposit is rather negligible compared to the more pronounced one forming at the second weir.

\section{Model for description of longitudinal shape of deposit}

\subsection{Parameterization of local bed aggradation}

For the parametrical description of the aggraded channel stretch near the side overflow, cross-sectional averaged longitudinal bed surface profiles (moving average, window length $3.50 \mathrm{~m}$ ) are used (Rosier 2007a) (Fig. 4). This profile represents the overall longitudinal trend of the mobile bed. The spanwise variation is not considered. A model taking into account both the streamwise and spanwise variation is presented in Rosier (2007b).

Since the aggraded channel reach is fully described by the maximum bed elevation $\left(z_{\max }^{*}\right)$, its location $\left(x_{\max }^{*}\right)$, shape $\left(n^{*}\right)$, and volume, a Maxwell-type distribution function represents a suitable approach:

$$
\text { [1] } Z(X)=\left(X \mathrm{e}^{1-X}\right)^{\mathrm{n}^{*}}
$$

where $n^{*}$ is the shape factor of the deposit and

$$
\text { [2] } \quad X=\frac{x *}{x_{\max }^{*}} \quad \text { and } Z=\frac{z *}{z_{\max }^{*}}
$$

are dimensionless parameters referring to the peak values $\left(x_{\max }^{*}, z_{\max }^{*}\right)$.

For increasing $n^{*}$ values, the shape of the deposit becomes more peaked, whereas for decreasing $n^{*}$ values, the deposit is wider and left skewed. By definition, the maxima of $X$ and $Z$ are located at 1.00 .

The formation and shape of the deposit is assumed to be influenced by the following four groups of parameters, which are used to express the input variables of the distribution function $\left(x_{\max }^{*}, z_{\max }^{*}, n^{*}\right)$ in terms of dimensionless relationships:

- geometry of main-channel,

- geometry of side weir,

- flow conditions, and

- bed-load transport.

For the analysis of the aggraded channel reach, the starting and end point of the deposit were defined as the local minima characterized by a clear and distinct change of slope compared to the profile upstream and downstream, respectively. By determining the vertical difference between the aggradation and the tangent between the two minima serving as a reference line, the net deposit is extracted. For the extracted deposit, the maximum elevation $\left(z_{\max }^{*}\right)$, its location $\left(x_{\max }^{*}\right)$, and the shape factor $\left(n^{*}\right)$ are defined, and the Maxwell distribution function is applied.

For the implementation of the bed evolution model into a numerical model, the location of the modelled deposit relative to the side weir has to be known $\left(x_{\mathrm{cp}}\right)$.

\subsection{Maximum elevation of extracted deposit $z_{\max }^{*}$}

Having the four groups of parameters mentioned in para- graph 4.1 in mind, the channel geometry, weir geometry, and flow conditions are represented by the ratio of the overflow to the approach discharge $\left(Q_{\mathrm{D}} / Q_{1}\right)$. The overflow discharge is expressed by the general equation of weirs, whereas the open-channel flow is given by the GaucklerManning-Strickler (GMS) equation:

[3] $\quad \frac{Q_{\mathrm{D}}}{Q_{1}}=\frac{2 / 3 C_{\mathrm{D}} \sqrt{2 g}\left(h_{1}-w_{\mathrm{D}}\right)^{3 / 2} L_{\mathrm{D}}}{R_{h, 1}^{2 / 3} n^{-1} S^{1 / 2} B h_{1}}$

where $Q_{\mathrm{D}}$ is overflow discharge, $Q_{1}$ is approach flow discharge, $C_{\mathrm{D}}$ is side weir discharge coefficient, $g$ is acceleration due to gravity, $h_{1}-w_{\mathrm{D}}=h_{\mathrm{D}, 1}$ is pressure head above side weir crest, $h_{1}$ is approach flow depth, $w_{\mathrm{D}}$ is weir height, $L_{\mathrm{D}}$ is weir crest length, $n$ is Manning resistance coefficient (here used including form roughness), $R_{\mathrm{h}, 1}$ is hydraulic radius $\left(R_{\mathrm{h}, 1} \approx h_{1}\right.$ for $\left.B / h_{1}>10\right), S$ is slope, and $B$ is channel width. The subscript 1 refers to the cross section at the upstream weir corner.

The bed-load intensity is entirely defined by the dimensionless Einstein factor $(\Phi)$ (Yalin 1972). The ratio of bed-load transport upstream and downstream of the weir is given by

$$
\text { [4] } \Delta \Phi=\frac{\Phi_{\text {downstream }}}{\Phi_{\text {upstream }}} \quad \text { where } \Phi=\frac{q_{\mathrm{sb}}}{\sqrt{(s-1) g d^{3}}}
$$

where $q_{\mathrm{sb}}$ is bed-load transport per unit width, $s$ is relative density, $g$ is acceleration due to gravity, and $d$ is characteristic grain diameter.

The average $\Delta \Phi$ ratio of 0.75 indicates that during the operation of the side weir, about $25 \%$ of the approach bedload material has been accumulated in the deposit.

To express $z_{\max }^{*}$ in a dimensionless way, the side weir pressure head $\left(h_{\mathrm{D}, 1}\right)$ has been chosen $\left(h_{\mathrm{D}, 1} / z_{\max }^{*}\right)$. A suitable expression for $h_{\mathrm{D}, 1} / z_{\max }^{*}$ has been found by applying the genetic program GPKernel (Genetic Programming Kernel) developed by Keijzer and Babovic (1999). In Table 2, the parameters used are summarized.

The introduction of the parameters $Q_{\mathrm{D}} / Q_{1}$ and $\Delta \Phi$ to the genetic program resulted in numerous relationships in the form $h_{\mathrm{D}, 1} / z_{\max }^{*}=f\left(Q_{\mathrm{D}} / Q_{1}, \Delta \Phi\right)$. Based on the physical meaning and the degree of correlation expressed in terms of $R^{2}$ values and after regroupment and omission of terms of minor influence, the following equation has been selected:

[5] $\frac{h_{\mathrm{D}, 1}}{z_{\max }^{*}}=\frac{\Delta \Phi}{Q_{\mathrm{D}} / Q_{1}}\left(3 \Delta \Phi-\frac{9}{5}\right)+\frac{9}{4}$

The application ranges for $h_{\mathrm{D}, 1} / z_{\max }^{*}, Q_{\mathrm{D}} / Q_{1}$, and $\Delta \Phi$ can be derived from Table 2. In Fig. 5, measured and computed $h_{\mathrm{D}, 1} / z_{\max }^{*}$ ratios are compared.

\subsection{Location of maximum elevation of extracted deposit $x_{\max }^{*}$}

To find a non-dimensional relationship for the location of the maximum height of the extracted deposit $\left(x_{\max }^{*}\right)$, the approach flow depth $\left(h_{1}\right)$ at the upstream weir edge has been used. The analysis showed that for all tests, $x_{\max }^{*}$ can be satisfactorily approached by 
Table 2. Overview of parameters used in the genetic program GPKernel for the development of eq. [5].

\begin{tabular}{llllllll}
\hline $\begin{array}{l}\text { No. of } \\
\text { run }\end{array}$ & $\begin{array}{l}\text { Pressure head, } \\
h_{\mathrm{D}, 1}(\mathrm{~m})\end{array}$ & $\begin{array}{l}\text { Max. height of } \\
\text { deposit, } z_{\max }^{*}(\mathrm{~m})\end{array}$ & $\begin{array}{l}\text { Relative height, } \\
h_{\mathrm{D}, 1} / z_{\max }^{*}(-)\end{array}$ & $\begin{array}{l}\text { Relative outflow, } \\
Q_{\mathrm{D}} / Q_{1}(-)\end{array}$ & $\begin{array}{l}\text { Upstream } \\
\Phi(-)\end{array}$ & $\begin{array}{l}\text { Downstream } \\
\Phi(-)\end{array}$ & $\begin{array}{l}\text { Ratio, } \\
\Delta \Phi(-)\end{array}$ \\
\hline B01 & 0.026 & 0.035 & 0.74 & 0.17 & 0.267 & 0.203 \\
B02 & 0.049 & 0.019 & 2.61 & 0.29 & 0.544 & 0.399 & 0.76 \\
B03 & 0.039 & 0.015 & 2.62 & 0.23 & 0.279 & 0.111 & 0.73 \\
B04 & 0.013 & 0.008 & 1.67 & 0.04 & 0.279 & 0.169 \\
B05 & 0.035 & 0.028 & 1.27 & 0.26 & 0.513 & 0.199 \\
B06 & 0.038 & 0.032 & 1.21 & 0.30 & 0.514 & 0.376 \\
C01 & 0.037 & 0.009 & 3.90 & 0.19 & 0.293 & 0.229 & 0.37 \\
C02 & 0.042 & 0.019 & 2.24 & 0.16 & 1.310 & 1.072 \\
C03 & 0.048 & 0.021 & 2.26 & 0.32 & 1.589 & 1.033 \\
C04 & 0.044 & 0.019 & 2.33 & 0.16 & 1.222 & 1.000 \\
C05 & 0.039 & 0.006 & 6.63 & 0.21 & 1.222 & 1.036 \\
D01 & 0.034 & 0.004 & 8.42 & 0.14 & 0.830 & 0.705 \\
D02 & 0.048 & 0.005 & 9.12 & 0.18 & 0.815 & 0.666 \\
D03 & 0.051 & 0.009 & 5.56 & 0.31 & 1.222 & 1.147 \\
D04 & 0.040 & 0.009 & 4.65 & 0.37 & 0.686 & 0.58 \\
D05 & 0.025 & 0.002 & 10.48 & 0.06 & 0.611 & 0.48 \\
\hline
\end{tabular}

Fig. 5. Comparison of measured and computed $h_{\mathrm{D}, 1} / z_{\max }^{*}$ ratios according to eq. [5]. The $95 \%$ confidence interval is shown as well.

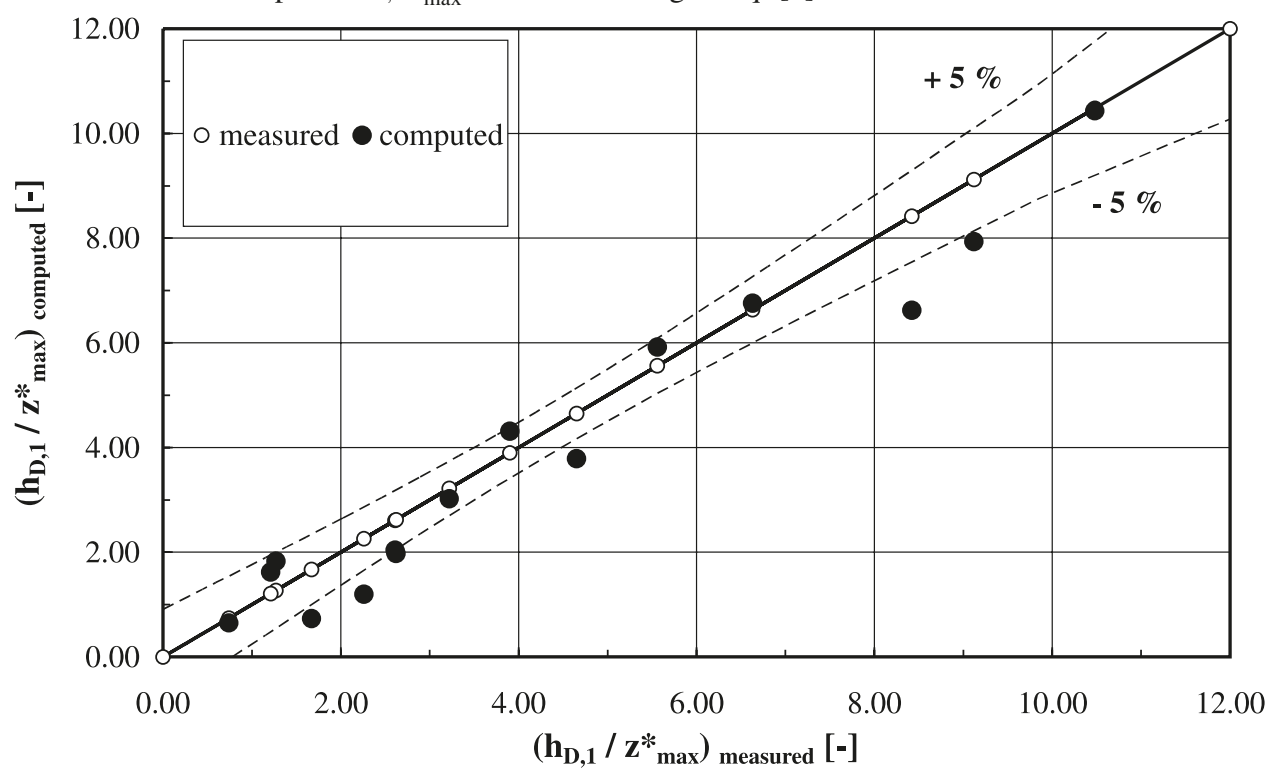

[6] $\frac{x_{\max }^{*}}{h_{1}} \approx 33$

applicable in a range of $18 \leq x_{\max }^{*} / h_{1} \leq 47$.

\subsection{Shape factor $n^{*}$ of extracted deposit}

It has been found that the shape factor $\left(n^{*}\right)$ is related to the ratio of side weir crest length $\left(L_{\mathrm{D}}\right)$ and channel width $(B)$ in the following way:

[7] $\quad n *=\frac{3}{4} \frac{L_{\mathrm{D}}}{B}+\frac{7}{3}$

The application range is given by $2.00 \leq L_{\mathrm{D}} / B \leq 4.00$.

\subsection{Implementation of extracted deposit into a flow calculation program}

Once the 2D-surface of the deposit is modelled, it has to be introduced into a flow calculation program. Since the position of the downstream weir corner (section 2) is usually known a priori, this point represents an appropriate reference or coupling point (Fig. 6).

For all experiments, the horizontal location of the maximum height of the deposit relative to the downstream weir corner $\left(x_{\mathrm{cp}}\right)$ varied in the following range:

$[8] \quad-0.65 \leq \frac{x_{\mathrm{cp}}}{L_{\mathrm{D}}} \leq 0.44$

The average ratio of $x_{\mathrm{cp}} / L_{\mathrm{D}}=-0.04$ indicates that the coupling point nearly coincides with the downstream weir corner. For computations in engineering practice, the downstream weir corner is recommended as an appropriate anchor point for the deposit. 
Fig. 6. Definition sketch for the implementation of the bed elevation model into a numerical program. The horizontal location of the maximum height of the deposit relative to the weir $\left(x_{\mathrm{cp}}\right)$ refers to the downstream weir corner (section 2).

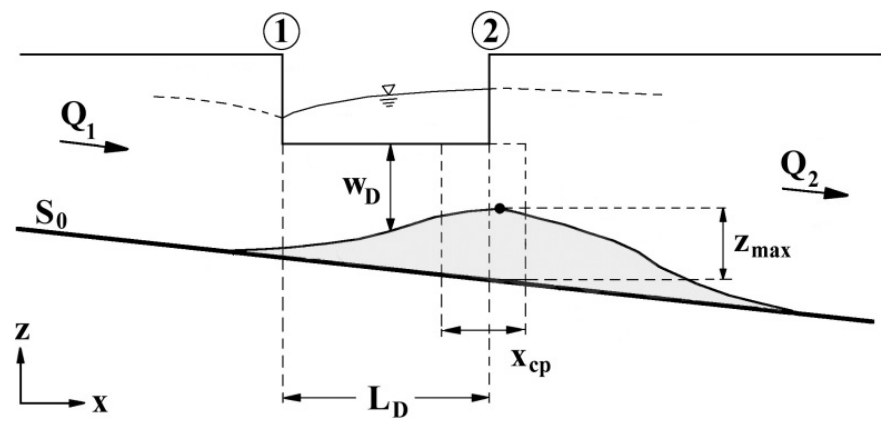

\section{Model for direct estimation of side overflow}

Instead of a determining the side overflow intensity by using the bed elevation model, for a predesign a first rough estimation of the overflow discharge might be both desirable as well as sufficient.

For the development of a simple direct calculation procedure, the side overflow intensity at the end of the experiments has been coupled with flat bed data from the initial experimental conditions. Hence, deposition phenomena are implicitly incorporated in the proposed equation.

The approach flow conditions $\left(Q_{1}\right)$ are expressed by the Gauckler-Manning-Strickler (GMS) equation, whereas the flow over the weir is described by the general equation of weirs $\left(Q_{\mathrm{D}}\right)$ (see eq. [3]). Both equations are made dimensionless using a Froude number:

[9] $\frac{Q_{1}}{B h_{1}^{3 / 2} \sqrt{g}}=F r_{1}$

$$
\frac{Q_{\mathrm{D}}}{L_{\mathrm{D}} h_{1}^{3 / 2} \sqrt{g}}=F r_{\mathrm{D}}
$$

where $F r_{1}$ is the approach flow Froude number and $F r_{\mathrm{D}}$ is the weir Froude number, since it is based on the overflow discharge and the weir crest length rather than the mainchannel discharge and the channel width.

Relating the ratio $F r_{\mathrm{D}} / F r_{1}$ to the side weir pressure head $\left(h_{\mathrm{D}, 1}\right)$ and the weir crest length $\left(L_{\mathrm{D}}\right)$ results in

$$
\frac{h_{\mathrm{D}, 1}}{L_{\mathrm{D}}}=0.037\left(\frac{F r_{\mathrm{D}}}{F r_{1}}\right)^{0.53}
$$

The application range is given by $0.004 \leq h_{\mathrm{D}, 1} / L_{\mathrm{D}} \leq 0.016$.

Usually, the parameters $h_{\mathrm{D}, 1}, L_{\mathrm{D}}$, and $F r_{1}$ are known or can be easily determined. The side overflow $\left(Q_{\mathrm{D}}\right)$ is then directly computed from eq. [10].

\section{Application of semi-empirical models on Rhone River in Switzerland}

To demonstrate the application procedure, the two empirical models are applied in a case study on the Rhone River upstream of Lake Geneva in Switzerland. Currently, the hy-
Fig. 7. Computation procedure for the bed elevation model to determine the shape of the deposit.

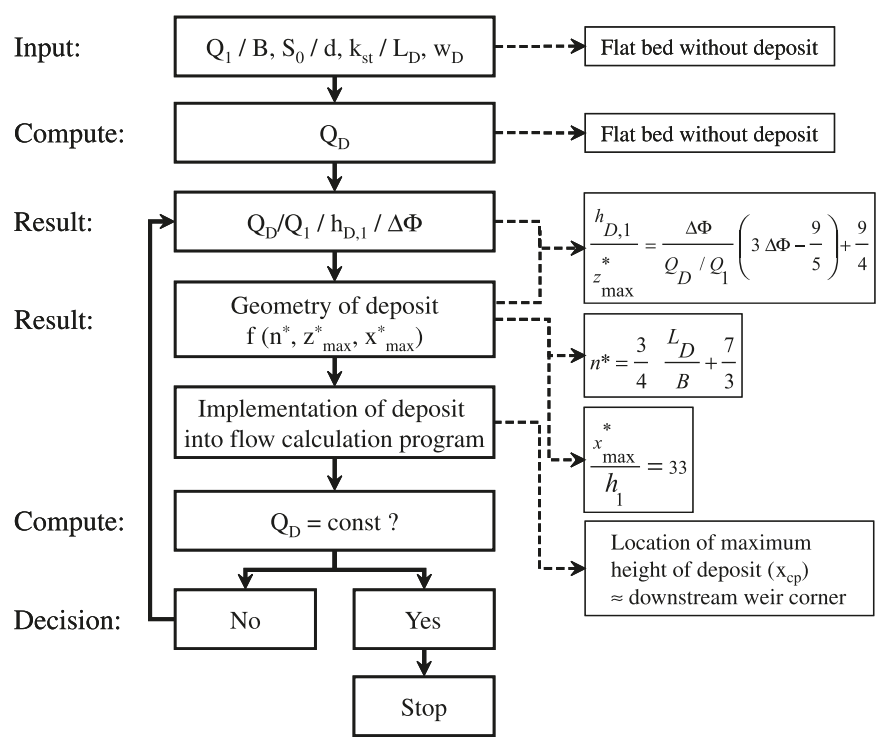

draulic capacity of the Rhone River is limited to a flood event with a 100 year return period $\left(\mathrm{HQ}_{100}=1260 \mathrm{~m}^{3} / \mathrm{s}\right)$. To increase the protection for an extreme flood with EHQ = $1600 \mathrm{~m}^{3} / \mathrm{s}$ and to handle the residual risk, a $L_{\mathrm{D}}=200 \mathrm{~m}$ long and $w_{\mathrm{D}}=7.35 \mathrm{~m}$ high side weir is supposed to be installed in the river dyke. For the computation, the $1 \mathrm{D}$ numerical code DUPIRO is used (Boillat et al. 2006). Identical results are obtained with the one-dimensional flow calculation program HEC-RAS. The characteristics of the Rhone River are given as $B=40 \mathrm{~m}, S_{0}=0.10 \%, d_{50}=$ $35 \mathrm{~mm}, d_{\mathrm{m}}=60 \mathrm{~mm}, n_{\text {grain }}=0.027 \mathrm{~s} / \mathrm{m}^{1 / 3}$, and $n_{\text {form }}=$ $0.030 \mathrm{~s} / \mathrm{m}^{1 / 3}$.

Since the ratios $Q_{\mathrm{D}} / Q_{1}$ and $\Delta \Phi$ in eq. [5] are not known a priori, an iterative procedure starting with flat bed conditions using eqs. [3] and [4] has to be performed. Based on the overflow discharge for the flat bed without deposit, the ratio $Q_{\mathrm{D}} / Q_{1}$ as well as the upstream and downstream $\Phi$ values, and hence $\Delta \Phi$, can be determined. The computation of $\Phi$ can be performed using bed-load transport equations, e.g., Meyer-Peter and Müller (1948). Once a stable overflow discharge $\left(Q_{\mathrm{D}}\right)$ is obtained, a stable deposit can be assumed and the iteration can be stopped. An overview of the calculation procedure is given in Fig. 7.

The initial side overflow for the flat bed with $z_{\max }^{*}=0.00 \mathrm{~m}$ and $Q_{1}=1600 \mathrm{~m}^{3} / \mathrm{s}$ (EHQ) yields $Q_{\mathrm{D}}=288 \mathrm{~m}^{3} / \mathrm{s}$ with $Q_{\mathrm{D}} / Q_{1}=$ $0.18, h_{\mathrm{D}, 1}=1.16 \mathrm{~m}, \Phi_{\text {upstream }}=0.035, \Phi_{\text {downstream }}=0.022$, and $\Delta \Phi=0.63$. After several iterations (here, eight iterations), the outflow becomes constant and a stable deposit is obtained (Figs. 8 and 9). The values after the last iteration step are $Q_{\mathrm{D}}=318 \mathrm{~m}^{3} / \mathrm{s}, Q_{\mathrm{D}} / Q_{1}=0.20, h_{\mathrm{D}, 1}=1.33 \mathrm{~m}, \Phi_{\text {upstream }}=$ $0.038, \Phi_{\text {downstream }}=0.019$, and $\Delta \Phi=0.50$. Consequently, the lateral outflow has increased by a factor of $\left(318 \mathrm{~m}^{3} / \mathrm{s}\right) /$ $\left(288 \mathrm{~m}^{3} / \mathrm{s}\right)=1.10$. The final height of the deposit is $z^{*}{ }_{\max }=$ 0.89 m. With $F r_{1}=0.486$ and $F r_{\mathrm{D}}=0.019$, the approach for direct estimation of the side overflow yields an outflow of $Q_{\mathrm{D}}=314 \mathrm{~m}^{3} / \mathrm{s}$, thus being close to the $2 \mathrm{D}$ bed elevation model. 
Fig. 8. Overflow discharge $\left(Q_{\mathrm{D}}\right)$ and main-channel discharge downstream of the side weir $\left(Q_{2}\right)$ for an approach discharge of $\mathrm{EHQ}=Q_{1}=1600 \mathrm{~m}^{3} / \mathrm{s}$. Iteration number 0 corresponds to the initial case of a flat bed without deposit.

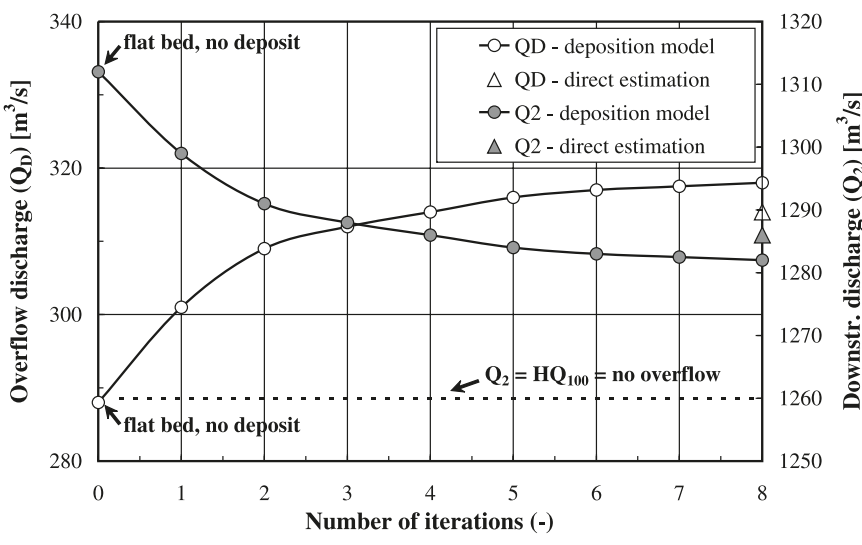

Fig. 9. Evolution of the shape of the deposit for different iteration steps.

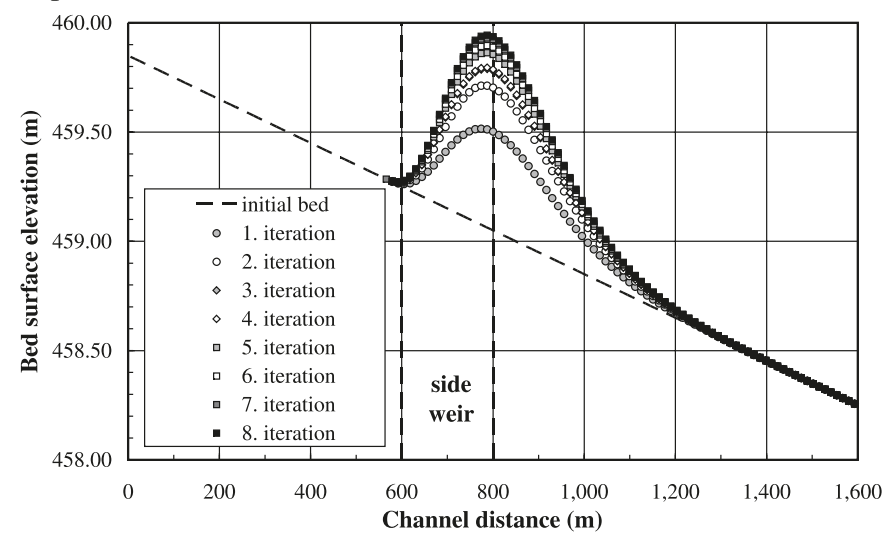

\section{Conclusions}

In the present study, the interaction of a side overflow with a mobile bed in a channel has been investigated experimentally. Owing to the lateral loss of water, the sediment transport capacity in the main-channel is significantly reduced within a rather short channel reach. As a consequence, sediments are deposited in the vicinity of the weir, and the side overflow increases in an uncontrolled way.

The longitudinal bed elevation near the weir is described by the help of a Maxwell distribution function. The main input parameters are the maximum bed elevation, its location, and a shape factor. The parameters are expressed in a nondimensional way, taking into account channel geometry, side weir geometry, flow conditions, and bed-load transport.

In addition, a simple approach for direct estimation of the side overflow has been developed. The resulting equation is based on the Manning formula and the general equation of weirs. The two models are applied in a case study on the Rhone River in Switzerland. Compared to flat bed conditions, the side overflow increases by about $10 \%$ when considering the morphological bed changes induced by the side weir. The method for direct estimation is in good agreement with the results of the $2 \mathrm{D}$ deposition model.

Implementing the semiempirical bed elevation model in a numerical code, steady flow simulations can be performed to estimate the spilled discharge, taking into account side overflow induced morphological bed changes.

The application range of the suggested models is given by the ratio of crest length to channel width, $2.00 \leq L_{\mathrm{D}} / B \leq$ 4.00 , the ratio of overflow to approach discharge, $0.04 \leq$ $Q_{\mathrm{D}} / Q_{1} \leq 0.37$, a relative bed roughness of $39 \leq h / d_{90} \leq 71$, a mild bottom slope, and a subcritical flow regime.

\section{Acknowledgements}

The authors would like to express their gratitude to the CTI (Swiss Innovation Promotion Agency, grant No. 4898.1) and FOEN (Swiss Federal Office for the Environment) for their sustained funding.

\section{References}

Boillat, J.-L., Dubois, J., and Nillipour, N. 2006. Migration of a dredging pit in the Rhone River. In River Flow 2006: Proceedings of the International Conference on Fluvial Hydraulics, 6-8 September 2006, Lisbon, Portugal. Edited by R.M.L. Ferreira, E.C.T.L. Alves, J.G.A.B. Leal, and A.H. Cardoso. Taylor and Francis, London. pp. 1193-1202.

Borghei, S.M., Jalili, M.R., and Ghodsian, M. 1999. Discharge coefficient for sharp-crested side weir in subcritical flow. Journal of Hydraulic Engineering, 125(10): 1051-1056. doi:10.1061/ (ASCE)0733-9429(1999)125:10(1051).

Crobeddu, E., and Bennis, S. 2006. Suivi et validation des measures pour un déversoir d'orage latéral à seuil court. Canadian Journal of Civil Engineering, 33(3): 326-335.

Ghodsian, M. 2003. Supercritical flow over a rectangular side weir. Canadian Journal of Civil Engineering, 30(3): 596-600. doi:10. 1139/103-004.

Hager, W.H. 1986. L'écoulement dans des déversoirs latéraux. Canadian Journal of Civil Engineering, 13(5): 501-509.

Hager, W.H. 1987. Lateral outflow over side weirs. Journal of Hydraulic Engineering, 113(4): 491-504. doi:10.1061/(ASCE)07339429(1987)113:4(491).

Keijzer, M., and Babovic, V. 1999. Dimensionally aware genetic programming. In Proceedings of the Genetic and Evolutionary Computation Conference (GECCO 1999), 13-17 July 1999, Orlando, Fla. Edited by W. Banzhaf, J.M. Daida, A.E. Eiben, M.H. Garzon, V. Honavar, M.J. Jakiela, and R.E. Smith. Morgan Kaufmann Publishers, San Fransisco, Calif.

Khorchani, M., and Blanpain, O. 2005. Development of a discharge equation for side weirs using artificial neural networks. Journal of Hydroinformatics, 7(1): 31-39.

Metflow. 2000. UVP monitor model UVP-XW user's guide. Metflow SA, Lausanne, Switzerland.

Meyer-Peter, E., and Müller, R. 1948. Formulas of bed-load transport. Report on the 2nd meeting of the IAHSR [today IAHR], Stockholm, Sweden. IAHR, Madrid, Spain. pp. 39-64.

Ranga Raju, K.G., Prasad, B., and Gupta, S.K. 1979. Side weir in rectangular channel. Journal of the Hydraulics Division, 105(5): 547-554.

Rosier, B. 2007a. Bed evolution due to lateral water withdrawal. In Proceedings of the 32nd IAHR Congress, 1-6 July 2007, Venice, Italy. [Abstractbook.] IAHR, Madrid, Spain. p. 788.

Rosier, B. 2007b. Interaction of a side weir overflow with bed-load transport and bed morphology in a channel. Ph.D. thesis 3872, Ecole Polytechnique Fédérale de Lausanne (EPFL), Lausanne, Switzerland. In Communication No. 34. Edited by A.J. Schleiss. Laboratory of Hydraulic Constructions (LCH), Ecole Polytechni- 
que Fédérale de Lausanne (EPFL), Lausanne, Switzerland. ISSN 1661-1179.

Rosier, B., Boillat, J.-L., and Schleiss, A.J. 2004. Mapping of bed morphology for lateral overflow using digital photogrammetry. In Proceedings of the 2nd International Conference on Scour and Erosion - ICSE-2, 14-17 November 2004, Singapore. Nanyang Technological University, Singapore.

Singh, R., and Satyanarayana, T. 1994. Automated field irrigation system using side weirs. Journal of Irrigation and Drainage Engineering, 120(1): 48-59. doi:10.1061/(ASCE)0733-9437(1994) 120:1(48).

Subramanya, K., and Awasthy, S.C. 1972. Spatially varied flow over side weirs. Journal of the Hydraulics Division, 98(HY1): $1-10$.

Yalin, M.S. 1972. Mechanics of sediment transport. Pergamon Press, Oxford.

\section{List of symbols}

$B$ channel width

$C_{\mathrm{D}}$ side weir discharge coefficient

$d$ characteristic grain diameter (usually $d_{50}$ )

$d_{\mathrm{m}}$ mean grain diameter

$d_{i}$ grain diameter for which $i \%$ of the sediment is finer by weight

$\mathrm{Fr}$ flow Froude number

$F r_{\text {D }}$ weir Froude number

$g$ acceleration due to gravity

$h$ low depth

$h_{\mathrm{D}}$ side weir pressure head, flow depth above side weir crest

$L_{\mathrm{D}}$ side weir crest length

$n$ Manning's resistance coefficient
$n_{\mathrm{D}}$ number of side weirs

$n^{*}$ shape factor

$q_{\mathrm{sb}}$ solid discharge (bed-load) per unit width

$Q_{1}$ approach discharge

$Q_{\text {D }}$ overflow discharge

$Q_{\text {sb }}$ solid discharge (bed-load) per unit weight

$p$ porosity of sediment

$R_{\mathrm{h}}$ hydraulic radius

$s$ relative density

$S$ slope

$S_{0}$ bed slope

$t$ time

$w_{\mathrm{D}}$ weir crest height

$x$ direction of rectilinear flow, channel distance

$x_{\mathrm{cp}}$ location of the coupling point relative to the downstream weir corner

$x^{*}$ location of deposition height of extracted deposit

$X$ dimensionless parameter in the Maxwell distribution function

$y$ direction horizontally perpendicular to $x$

$z$ direction vertically perpendicular to $x$

$z^{*}$ deposition height of extracted deposit

$Z$ dimensionless parameter in the Maxwell distribution function

$\Delta \Phi$ ratio of downstream to upstream bed-load discharge

$\rho_{\mathrm{S}}$ density of sediment

$\sigma_{\mathrm{g}}$ geometric sorting coefficient $\left[=\left(d_{84} / d_{16}\right)^{1 / 2}\right]$

$\Phi$ dimensionless intensity of bed-load discharge, Einstein factor

1,2 suffixes designating the beginning and the end of the side weir

ini, fin initial, final

max marks the maximum value of a quantity 